\title{
Estratégias de mediação para o conto e reconto de histórias para alunos surdos
}

Ana Claudia Tenor* Débora Deliberato**

\section{Resumo}

O objetivo deste estudo foi descrever estratégias de mediação em atividades de conto e reconto de histórias para alunos surdos. Participaram da pesquisa dois alunos surdos e suas respectivas professoras, sendo uma da educação infantil e outra do ensino fundamental, de um município do interior de São Paulo. A pesquisadora conversou e planejou em conjunto aos professores os contos que seriam trabalhados. As histórias foram adaptadas por meio Picture Communication Symbols (Mayer-Johnson, 2004) e foram utilizados fantoches, dedoches, dramatização e apresentaçâo dos sinais em Libras. Foram empregados registro contínuo e filmagens das atividades desenvolvidas em sala de aula. Os dados dos registros foram incorporados aos dados das filmagens, foi feita triangulação e análise de conteúdo. Foram identificadas as seguintes categorias e subcategorias de análise: 1- Participação dos alunos: alunos surdos, alunos ouvintes; 2- participação das professoras: professora de educação infantil, professora de ensino fundamental; 3- modalidade de comunicaçáo dos alunos surdos: oral- auditiva, visoespacial, bimodalidade; 4- estratégias de comunicação da mediadora: língua oral, comunicação bimodal; 5- recursos apoiados nos sistemas gráficos: suplementares e alternativos de comunicação, demais recursos. As estratégias de mediaçōes e os recursos adotados propiciaram maior interaçáo e a participação tanto dos alunos ouvintes como surdos dentro das atividades programadas. No entanto, considera-se importante o ensino de Língua de Sinais aos alunos com surdez e a inserção do intérprete de Libras no contexto da sala de aula.

Palavras-chave: Educação Especial; Contação de histórias; Aluno surdo.

* Doutora em Educação pela Universidade Estadual Paulista Júlio de Mesquita Filho, Marília, São Paulo, Brasil.

** Professora doutora da Universidade Estadual Paulista Júlio de Mesquita Filho, Marília, Sáo Paulo, Brasil. 


\section{Mediation strategies for the tale and retelling stories for deaf}

\section{Abstract}

The aim of this study was to describe strategies on mediation activities for tales and retelling stories for deaf students. The participants were two deaf students and their teachers in a kindergarten and at an elementary school in an inland city of São Paulo State. The tales to be worked with have been planned and agreed among the teachers and the researcher. The stories have been adapted by the Picture Communication Symbols (Mayer-Johnson, 2004) and puppets have been used, as well as role playing and presentation of signals in Libras. Continuous recording have been applied and the activities developed in the classroom have been filmed. The data records have been added to the filming data. Triangulation and content analysis have also been done. The following categories and subcategories of analysis were identified: 1- Student participation: deaf students, hearing students; 2- participation of teachers: teacher from kindergarten, elementary school teacher; 3- mode of communication of deaf students: hearing orally, visuospatial, bimodality; 4- communication strategies of mediation: oral language, bimodal communication; 5- resources supported in graphic systems: additional and alternative communication and other resources. Mediation strategies and adopted resources promote better interaction and better participation from both listeners and deaf students within the scheduled activities. However, teaching sign language to students with deafness is considered quite important and also the insertion of the Sign Language interpreter into the context of the classroom.

Keywords: Special Education; Storytelling; Deaf student.

\section{Introdução}

O tema surdez e linguagem e o impacto da falta de um sistema de representação linguística para o desenvolvimento cognitivo, emocional e social da criança surda têm sido debatidos por pesquisadores da área (GOLDFELD, 2001; MOURA, 2013).

Conforme a literatura, o desenvolvimento da linguagem requer a capacidade de compreender e utilizar formas e estruturas linguísticas, sendo elemento importante no domínio gradativo da criança surda sobre o mundo. Aquelas que se encontram em fases iniciais do desenvolvimento de linguagem podem apresentar capacidades linguísticas e de comunicação limitadas, necessitando, portanto, de membros mais competentes da cultura para exercer e manter interaçóes comunicativas que contribuam para o seu desenvolvimento (VON TETZCHNER et al. 2005; VON TETZCHNER, 2009).

O desenvolvimento do discurso narrativo é considerado de extrema importância para o processo de aquisição da linguagem e o adulto desempenha importante papel no desenvolvimento das habilidades narrativas da criança. É por meio da nar- 
ração que a criança organiza seu passado (re) elaborando os fatos de sua experiência pessoal e o adulto colabora ao compartilhar noções de relevância narrativa, alocar turnos narrativos, suportar ou questionar a validade da história e da performance da criança e fazer perguntas eliciadoras (PERRONI, 1992; DADALTO; GOLDFELD, 2009; GEUSELI, 2009).

Souza e Bernardino (2011) evidenciaram que a atividade de contos de histórias é uma estratégia pedagógica que pode favorecer de maneira significativa a prática docente na educação infantil e ensino fundamental. A escuta de histórias estimula a imaginaçáo, educa, instrui, desenvolve habilidades cognitivas, dinamiza o processo de leitura e escrita, além de ser uma atividade interativa que potencializa a linguagem infantil.

As estratégias de mediação utilizadas pelo professor nas diversas atividades de ensino, tais como o reconto de histórias, podem favorecer o aprendizado do aluno. Nesse contexto, o mediador tem como funçáo auxiliar o professor a pensar em atividades e confeccionar materiais pedagógicos que promovam o desenvolvimento do aluno com deficiência, assim como sua participação, sempre respeitando suas limitaçôes e potencialidades (SILVA; MANZINI; DELIBERATO, 2009; OBELAR, 2011).

Os estudos desenvolvidos com crianças usuárias de sistemas alternativos de comunicação evidenciaram a necessidade de estimular as habilidades narrativas nessas crianças. Nesse sentido, os pesquisadores têm utilizado as narrativas como estratégias para a aquisiçấo e o desenvolvimento das habilidades linguísticas dos usuários de comunicação gráfica por meio da mediação de um interlocutor (NUNES et al. 2003; VON TETZCHNER, 2003; GUARDA; DELIBERATO, 2006; PONSONI, 2010; DELGADO, 2011; MEDINA; DELIBERATO, 2014).

Tratando-se de crianças surdas, o desenvolvimento da linguagem pode ser muito comprometido se elas não tiverem oportunidades de desenvolvimento em língua de sinais (LACERDA; LODI, 2006; HACHIMINE, 2006).

A utilização da língua de sinais, enquanto uma atividade mediadora para o letramento, no ambiente escolar, é um recurso potencial em produção de conhecimento. $\mathrm{O}$ uso do relato, do diálogo e de outras manifestaçóes como a expressão, a dramatização, expressões faciais e corporais caracterizam esse desenvolvimento (SILVA; MEDEIROS; LORENSI, 2010).

A literatura evidenciou que o apoio visual é de suma importância para a garantia do processo de aprendizagem e interpretação do texto ao aluno surdo. Nesse sentido, para favorecer a aprendizagem dos alunos surdos, os professores devem utilizar recursos visuais de comunicação que sirvam de apoio à informação transmitida, tais como desenho, leitura, vídeo, cartaz (BRASIL, 2007; PINOTTI; BOSCOLO, 2008; MERSELIAN; VITALIANO, 2011).

É notória a importância do discurso narrativo para o desenvolvimento da linguagem, e tratando-se de alunos com deficiência há necessidade de recursos e estratégias para aquisição da narrativa. Os sistemas gráficos têm sido utilizados para 
alunos com deficiência sem oralidade, que muitas vezes já têm a aquisição de um sistema linguístico (Língua Portuguesa). Sendo assim, os sistemas visuais colaboram na produção da narrativa e poderiam ser um instrumento favorecedor para aquisição da narrativa do aluno surdo, em função dos marcadores visuais oferecidos para as questôes de sentido e de organização do pensamento.

\section{Objetivo}

Descrever estratégias de mediação em atividades de conto e reconto de histórias para alunos surdos.

\section{Método}

\section{Procedimentos éticos}

De acordo com as recomendaçóes da Resolução 196/96 do Conselho Nacional de Saúde, a pesquisa foi aprovada por um Comitê de Ética sob o protocolo n ${ }^{\circ}$ 0351/2011. As duas professoras e os pais dos alunos selecionados assinaram o Termo de Consentimento Livre e Informado para autorizaçáo da realização do estudo.

\section{Participantes}

Participaram da pesquisa dois alunos surdos e duas professoras que atuavam com aluno surdo incluído, sendo uma da educação infantil e outra do ensino fundamental, de um município do interior de São Paulo. Para identificação dos sujeitos, foi usado A1 (aluno surdo), A2 (aluna surda), PRO1 (professora do ensino fundamental) e PRO2 (professora de educação infantil).

\section{Local}

As atividades de mediaçóes por meio de conto e reconto de histórias foram desenvolvidas no período de setembro a novembro de 2012, em duas escolas do interior de São Paulo, sendo uma escola de educação infantil e outra de ensino fundamental, com os professores e alunos selecionados.

\section{Características dos participantes}

A professora do Ensino Fundamental (PRO1) tinha 55 anos de idade e 35 anos de experiência docente, lecionou durante um ano em classe especial, mas sem ter realizado cursos de formação nessa área; era a primeira vez que atuava com aluno surdo (A1). A1, aluno do gênero masculino, tinha seis anos de idade, recebeu o diagnóstico de deficiência auditiva neurossensorial profunda bilateral com dois anos e seis meses, fazia uso de implante coclear há quatro anos e do sistema FM em sala de aula há seis meses. A1 compreendia ordens verbais simples e os comandos rotineiros da escola sem o apoio de gestos, comunicava-se por meio de gestos espontâneos, vocalizaçôes e dramatizaçôes. O aluno apresentava pouco contato visual com o interlocutor e não mantinha atenção visual enquanto a professora ensinava as tarefas em sala de aula. 
A professora de Educação Infantil (PRO2) tinha 32 anos de idade e dois anos de experiência em sala de aula, durante sua graduaçáo em pedagogia fez um curso de extensão em Libras de 40 horas e atuava pela primeira vez com a aluna surda (A2). O aluno $\mathrm{A} 2$, do gênero feminino, cinco anos de idade, teve o diagnóstico de deficiência auditiva neurossensorial profunda bilateral com quatro anos de idade, fazia uso de implante coclear há um ano e sete meses. A2 detectava sons, mas não compreendia ordens verbais simples e os comandos rotineiros da escola sem o apoio de gestos, fazia uso da leitura orofacial, comunicava-se por meio de gestos espontâneos e vocalizaçóes. A2 apresentava atenção visual ao interlocutor, mas não a mantinha enquanto a professora ensinava as tarefas em sala de aula.

\section{Materiais e equipamentos}

Foram utilizados os seguintes materiais e equipamentos para a coleta de dados: filmadora com tripé para filmar as mediaçóes em sala de aula, máquina fotográfica para fotografar os recursos utilizados, caderno brochura para anotar as mediaçóes, placas de Eucatex, pranchas pequenas de comunicação alternativa, o software Boardmaker (Mayer- Johnson, 2004) para a confecção dos símbolos gráficos do Picture Communication Symbols (PCS), referente às histórias trabalhadas. Também foram utilizados fantoches, dedoches, marionete, adereços, máscaras e fantasias dos personagens.

\section{Formas de registro}

Foram empregadas duas formas de registro: registro contínuo e filmagem das atividades desenvolvidas em sala de aula.

\section{Procedimento de coleta de dados}

Para o desenvolvimento das atividades de mediação, foi necessária a elaboração de um cronograma contendo a sequência das atividades planejadas. A pesquisadora inicialmente observou o professor e aluno surdo em sala de aula e posteriormente conversou e planejou em conjunto aos professores os contos de histórias que seriam trabalhados.

$\mathrm{Na}$ escola de educaçáo infantil, foram desenvolvidas 12 atividades de mediaçóes, e os contos trabalhados foram: "Os Três Porquinhos", "Chapeuzinho Vermelho", "Pinóquio" e "Branca de Neve".

$\mathrm{Na}$ escola de ensino fundamental, a pesquisadora desenvolveu 13 atividades de mediaçôes, iniciando com a fábula "O Rato do Campo e o Rato da Cidade" por ser uma atividade planejada nessa sala. Em seguida, contou as mesmas histórias apresentadas a educação infantil porque a professora considerou importante o desenvolvimento do trabalho com os contos clássicos nas séries iniciais de alfabetização. 


\section{Procedimentos de mediação nas atividades de contos e recontos de histórias em sala de aula}

Os quadros 1 e 2 ilustram as sequências de atividades desenvolvidas nas escolas de educaçáo infantil e ensino fundamental, a modalidade de comunicação adotada pela pesquisadora e os recursos utilizados.

Quadro 1 - Atividades desenvolvidas na Escola de Educação Infantil e recursos utilizados.

\begin{tabular}{|c|c|c|}
\hline Atividade & Comunicaçáo & Recursos \\
\hline Os Três Porquinhos & Língua oral & Prancha com sequência de figuras do PCS. \\
\hline Os Três Porquinhos & Bimodal & Fantoches dos três porquinhos, lobo e palco. \\
\hline Chapeuzinho Vermelho & Bimodal & $\begin{array}{l}\text { Prancha com sequência de figuras da } \\
\text { Chapeuzinho Vermelho do PCS. }\end{array}$ \\
\hline Chapeuzinho Vermelho & Bimodal & $\begin{array}{l}\text { Prancha com sequência de figuras da } \\
\text { Chapeuzinho Vermelho do PCS. }\end{array}$ \\
\hline Chapeuzinho Vermelho & Bimodal & $\begin{array}{l}\text { Prancha confeccionada, cenário de floresta de } \\
\text { EVA e sequência de figuras da Chapeuzinho } \\
\text { Vermelho do PCS. }\end{array}$ \\
\hline Chapeuzinho Vermelho & Bimodal & $\begin{array}{l}\text { Fantoches do chapeuzinho vermelho, lobo, } \\
\text { vovó, caçador e palco. }\end{array}$ \\
\hline Pinóquio & Bimodal & $\begin{array}{l}\text { Prancha com sequência de figuras da } \\
\text { história do livro do Pinóquio e marionete do } \\
\text { Pinóquio. }\end{array}$ \\
\hline Pinóquio & Bimodal & $\begin{array}{l}\text { Prancha com sequência de figuras do } \\
\text { Pinóquio do PCS }\end{array}$ \\
\hline Pinóquio & Bimodal & $\begin{array}{l}\text { Fantoches do Pinóquio, Gepeto e homem } \\
\text { do circo, fada azul confeccionada e colada } \\
\text { no EVA e palco. }\end{array}$ \\
\hline Branca de Neve & Bimodal & $\begin{array}{l}\text { Prancha com sequência de figuras da Branca } \\
\text { de Neve do PCS. }\end{array}$ \\
\hline $\begin{array}{l}\text { Branca de Neve e } \\
\text { Chapeuzinho Vermelho }\end{array}$ & Bimodal & $\begin{array}{l}\text { Prancha com sequência de figuras da Branca } \\
\text { de Neve do PCS e prancha com sequência de } \\
\text { figuras da Chapeuzinho Vermelho do PCS. }\end{array}$ \\
\hline $\begin{array}{l}\text { Branca de Neve e } \\
\text { Chapeuzinho Vermelho }\end{array}$ & Bimodal & $\begin{array}{l}\text { Prancha confeccionada, cenário de floresta } \\
\text { de EVA, sequência de figuras da Branca } \\
\text { de Neve do PCS, fantoches da Branca de } \\
\text { Neve, príncipe, bruxa e dedoches dos sete } \\
\text { anôes. Prancha com a sequência de figuras } \\
\text { da Chapeuzinho Vermelho do PCS. }\end{array}$ \\
\hline
\end{tabular}

Fonte: produção do próprio autor. 
Quadro 2 - Atividades desenvolvidas na Escola de Ensino Fundamental e recursos utilizados

\begin{tabular}{|c|c|c|}
\hline Atividade & Comunicaçáo & Recursos \\
\hline $\begin{array}{l}\text { O rato do campo e o rato da } \\
\text { cidade }\end{array}$ & Língua oral & $\begin{array}{l}\text { Prancha com sequência de } \\
\text { figuras do PCS. }\end{array}$ \\
\hline Os Três Porquinhos & Língua oral & $\begin{array}{l}\text { Prancha com sequência de } \\
\text { figuras do PCS. }\end{array}$ \\
\hline Os Três Porquinhos & Língua oral & $\begin{array}{l}\text { Fantoches dos três } \\
\text { porquinhos, lobo e palco. }\end{array}$ \\
\hline Os Três Porquinhos & Bimodal & $\begin{array}{l}\text { Fantoches dos três } \\
\text { porquinhos, lobo, palco e } \\
\text { prancha com sequência de } \\
\text { figuras do PCS. }\end{array}$ \\
\hline Chapeuzinho Vermelho & Bimodal & $\begin{array}{l}\text { Prancha com sequência de } \\
\text { figuras do PCS. }\end{array}$ \\
\hline Chapeuzinho Vermelho & Bimodal & $\begin{array}{l}\text { Fantoches do Chapeuzinho } \\
\text { Vermelho, vovó, caçador, } \\
\text { lobo e palco. }\end{array}$ \\
\hline Chapeuzinho Vermelho & $\begin{array}{l}\text { Língua oral e interpretaçáo } \\
\text { em Libras }\end{array}$ & $\begin{array}{l}\text { Prancha confeccionada, } \\
\text { cenário de floresta de } \\
\text { EVA, sequência de figuras } \\
\text { da história Chapeuzinho } \\
\text { Vermelho do PCS, intérprete } \\
\text { de Libras. }\end{array}$ \\
\hline Pinóquio & Bimodal & $\begin{array}{l}\text { Prancha confeccionada, } \\
\text { cenário da história Pinóquio, } \\
\text { figuras do Pinóquio, Gepeto } \\
\text { e fada azul coladas no EVA } \\
\text { marionete do Pinóquio e } \\
\text { sequência de figuras do livro } \\
\text { do Pinóquio. }\end{array}$ \\
\hline Pinóquio & Bimodal & $\begin{array}{l}\text { Prancha com sequência de } \\
\text { figuras do PCS da história } \\
\text { Pinóquio. }\end{array}$ \\
\hline Pinóquio & Bimodal & $\begin{array}{l}\text { Confecção de máscaras do } \\
\text { Pinóquio e Gepeto, capa } \\
\text { de tule azul da fada azul, } \\
\text { varinha da fada e confecçấo } \\
\text { da baleia no papel cartáo. }\end{array}$ \\
\hline Branca de Neve & Bimodal & $\begin{array}{l}\text { Prancha com sequência de } \\
\text { figuras da história Branca de } \\
\text { Neve. }\end{array}$ \\
\hline
\end{tabular}


Continuação Quadro 2

\begin{tabular}{|l|l|l|}
\hline Branca de Neve & Bimodal & $\begin{array}{l}\text { Prancha com sequência de } \\
\text { figuras da história Branca de } \\
\text { Neve, fantoches da branca } \\
\text { de Neve, bruxa e príncipe, } \\
\text { miniatura de maçấ, seringa } \\
\text { e veneno. }\end{array}$ \\
\hline Branca de Neve & $\begin{array}{l}\text { Máscaras da Branca de Neve, } \\
\text { dos anóes Dengoso, Soneca, } \\
\text { Zangado, Dunga, Atchim, } \\
\text { Feliz e Mestre, espelho azul, } \\
\text { coroa da rainha, coroa do } \\
\text { príncipe, nariz de bruxa, } \\
\text { chapéu de caçador, capa de } \\
\text { cetimvermelho para príncipe, } \\
\text { capas de tule vermelha para } \\
\text { rainha, amarela para Branca } \\
\text { de Neve e preta para bruxa. } \\
\text { Participaçáo do intérprete de } \\
\text { Libras. }\end{array}$ \\
\hline & Língua oral e interpretaçă \\
em Libras
\end{tabular}

Fonte: produção do próprio autor.

\section{Procedimentos de análise dos dados}

As atividades de mediaçôes desenvolvidas em sala de aula por meio de conto e reconto de histórias foram registradas em vídeos e a pesquisadora também anotou em caderno de registro. A pesquisadora assistiu as filmagens, transcreveu os vídeos e incorporou o material advindo das anotaçôes do caderno de registro às transcriçôes dos vídeos, triangulando os dados conforme Triviños (1992). Em seguida, foi feita análise de conteúdo segundo Bardin (2004) e identificada as seguintes categorias e subcategorias de análise: 1- participação dos alunos: alunos surdos, alunos ouvintes; 2- participação das professoras: professora de educação infantil, professora de ensino fundamental; 3- modalidade de comunicação dos alunos surdos: oral- auditiva, visoespacial, bimodalidade; 4- estratégias de comunicação da mediadora: língua oral, comunicação bimodal; 5- recursos apoiados nos sistemas gráficos: suplementares e alternativos de comunicaçáo, demais recursos. As categorias identificadas foram encaminhadas para avaliação a dois juízes com experiência na área da Educação Especial, obtendo índice de concordância favorável segundo Carvalho (1996). A seguir estão descritas as definiçóes das categorias e subcategorias de análises estabelecidas.

\section{Categoria 1 - Participaçáo dos alunos}

Esta categoria diz respeito a participação dos alunos surdos e ouvintes durante as atividades de conto e reconto de histórias desenvolvidas em sala de aula.

1.1. Alunos surdos: foi considerada a participação e interação dos alunos surdos durante as atividades de conto e reconto de histórias. 
1.2. Alunos ouvintes: foi considerada a participação e interação dos alunos ouvintes durante as atividades de conto e reconto de histórias.

\section{Categoria 2 - Participaçáo das professoras}

Refere-se a participação e interação das professoras durante as atividades de mediaçôes desenvolvidas por meio do conto de histórias.

2.1. Professora de Educação Infantil: diz respeito a participação e envolvimento da professora de educaçâo infantil junto a mediadora e aos alunos durante as atividades de contos desenvolvidas em sala de aula.

2.2. Professora de Ensino Fundamental: diz respeito a participação e envolvimento da professora de ensino fundamental junto a mediadora e aos alunos durante as atividades de contos desenvolvidas em sala de aula.

\section{Categoria 3 - Modalidade de comunicaçáo dos alunos surdos}

Foi considerada a modalidade de comunicação usada pelo aluno surdo durante as atividades de conto de histórias.

3.1. Oral- auditiva: Segundo Barbosa e Lichtig (2014), essa modalidade refere-se a ocorrência de comunicação por meio da língua oral ou vocalizaçóes.

3.2. Visoespacial: Segundo Barbosa e Lichtig (2014), essa modalidade refere-se a ocorrência de comunicação por meio da Língua de Sinais ou gestos.

3.3. Bimodal: Segundo Barbosa e Lichtig (2014), refere-se a ocorrência de mais de uma modalidade em um mesmo evento, ou seja, modalidade associada: língua de sinais, gestos, língua oral e vocalizações.

\section{Categoria 4 - Estratégias de comunicaçáo da mediadora}

Esta categoria refere-se a modalidade de comunicação usada pela mediadora durante as atividades de conto e reconto de histórias.

4.1. Língua oral: foi considerada a estratégia de comunicação adotada pela mediadora durante o conto e reconto de histórias por meio do uso da língua oral.

4.2. Comunicação bimodal: foi considerada a estratégia de comunicação adotada pela pesquisadora durante o conto e reconto de história por meio do uso associado da língua oral e língua de sinais.

\section{Categoria 5 - Recursos apoiados nos sistemas gráficos}

Foram considerados os recursos utilizados pela pesquisadora durante as atividades de conto e reconto de história em sala de aula.

5.1. Suplementares e alternativos de comunicação: foram consideradas as figuras de histórias confeccionadas por meio de recursos de tecnologia assistiva, o Picture 
Communication Symbols (PCS) e outras figuras referentes aos contos infantis selecionados.

5.2. Demais recursos: refere-se aos fantoches, dedoches, máscaras e fantasias dos personagens utilizados durante a dramatizaçấo dos contos de histórias.

\section{Resultados e discussão}

A seguir serão apresentados os resultados referentes às categorias estratégicas de comunicação da mediadora e recursos usados para mediação.

Exemplo 1 - Categoria: Estratégias de comunicação da mediadora

Subcategoria: Língua oral

Contexto: Mediação da pesquisadora em sala de aula de Ensino Fundamental durante o conto da história "Os Três Porquinhos".

A pesquisadora narrou a história oralmente e fez uso dos fantoches dos três porquinhos, lobo mau e as figuras coloridas das casas de palha, de madeira e tijolo. Enquanto narrava a história, os alunos ouvintes interagiam e respondiam as perguntas feitas pela pesquisadora. $\mathrm{O}$ aluno surdo (A1) prestou atenção durante toda a atividade, olhou os fantoches, sorriu e interagiu junto aos alunos ouvintes quando a pesquisadora solicitou aos alunos para assoprarem junto ao lobo a casa de palha, de madeira e de tijolo.

No contexto escolar, as histórias atuam como instrumentos favorecedores da interação entre o aluno e professor, mas, principalmente, como um recurso pedagógico importante no processo de ensino e aprendizagem, pois as narraçóes de histórias infantis, na pré- escola, colaboram para o processo de aquisiçáo do discurso narrativo, proporcionando o desenvolvimento da leitura e escrita, além de estimular o imaginário (PONSONI, 2010).

Exemplo 2 - Categoria: Estratégias de comunicação da mediadora

Subcategoria: Comunicação bimodal

Contexto: Mediação da pesquisadora em sala de aula de Educação Infantil durante o conto e reconto de história "Chapeuzinho Vermelho".

A atividade foi desenvolvida com a participação dos alunos ouvintes, de A2 (aluna surda) e de PRO2. A pesquisadora usou a comunicação bimodal, pois se tratava de inclusão de uma aluna surda em sala de ouvintes, sem o apoio do intérprete de Libras. Os recursos empregados foram: uma prancha de papeláo contendo o cenário da floresta e as sequências de figuras da história, confeccionadas por meio do PCS. A pesquisadora posicionou a prancha na mesa da professora, à frente da sala, narrou a história oralmente e simultaneamente fez os sinais dos personagens, dos verbos e demais léxicos. PRO2 posicionou-se ao lado da prancha e auxiliava a pesquisadora repetindo os sinais apresentados e oferecendo o modelo à classe. 
Ao finalizar a história, a pesquisadora perguntou os sinais referentes ao vocabulário da história. Quando os alunos não se recordavam, oferecia o modelo e PRO2 participava junto aos alunos.

Exemplo 3 - Categoria: Recursos apoiados nos sistemas gráficos

Subcategoria: Suplementares e alternativos de comunicaçáo

Contexto: Mediação da pesquisadora em sala de aula de Educação Infantil durante o conto da história "Pinóquio".

A pesquisadora contou a história "Pinóquio" com o apoio da prancha confeccionada contendo as imagens dos personagens e a sequência de figuras do livro do Pinóquio. Em seguida, solicitou a cinco alunos para se dirigirem a frente, entre eles estava A2 (aluna surda). A pesquisadora apresentava as figuras dos personagens a cada aluno e solicitava para que fizessem os sinais em Libras referentes aos personagens.

Os recursos visuais, tais como fotos, imagens ou objetos concretos são considerados importantes para a alfabetização de surdos e devem ter caráter de apoio para a aprendizagem, principalmente ilustrar conteúdos novos e desconhecidos. A recomendação para seu uso é que, junto à imagem, sempre esteja a palavra escrita (BRASIL, 2007; PINOTTI; BOSCOLO, 2008; MERSELIAN; VITALIANO, 2011).

Exemplo 4 - Categoria: Recursos apoiados nos sistemas gráficos

Subcategoria: Demais recursos

Contexto: Dramatização da história Pinóquio em sala de aula do Ensino Fundamental com a participaçáo dos alunos.

A pesquisadora narrou a história oralmente e os aluno dramatizaram usando máscaras e fantasias, sendo que a dramatizaçáo foi apresentada duas vezes. Na primeira apresentação, A1 (aluno surdo) usou a máscara do Pinóquio, um aluno ouvinte usou a máscara do Gepeto, uma aluna ouvinte foi a fada azul e usou capa azul e varinha prateada confeccionada no papel cartáo, uma aluna ouvinte representou a baleia e segurou a baleia grande confeccionada no papel cartáo, dois alunos ouvintes representaram os ladróes e usaram uma venda preta nos olhos, um aluno ouvinte representou o homem do circo e usou chapéu branco. Durante a segunda dramatizaçáo, outros alunos que não haviam participado dramatizaram a história, o aluno A1 participou novamente e quis representar o ladrăo. As atividades que envolvem linguagem teatral, como as dramatizaçóes, são particularmente prazerosas para as crianças surdas, porque envolvem movimento corporal e expressóes faciais. Essa população tem uma excelente expressão dramática, usa os movimentos do corpo, da expressão facial, que parece ser potencializada a partir das atividades envolvendo dramatizaçôes com histórias infantis (SILVA; MEDEIROS; LORENSI, 2010). 


\section{Conclusão}

A identificação prévia das habilidades linguísticas dos alunos surdos foi fundamental para a pesquisadora pensar em recursos e estratégias que pudessem contribuir com o aprendizado dos alunos e minimizar as dificuldades vivenciadas no processo de ensino e aprendizagem.

A pesquisadora buscou oferecer um modelo de suporte ao professor e aos alunos surdos, desenvolvendo atividades de mediaçóes por meio de conto e reconto de histórias, adaptando recursos e usando estratégias de comunicação visando facilitar a compreensão do aluno e possibilitar a sua participação dentro das atividades propostas em sala de aula. Como estratégias de comunicação e recursos visuais, foram usadas: comunicação oral e bimodal, confecção de sequências de histórias por meio do Picture Communication Symbols (PCS), dramatizaçōes das histórias fazendo uso de fantoches, dedoches e fantasias, com a intenção de facilitar a compreensão do aluno surdo durante as atividades de contos de histórias.

As estratégias de mediação adotadas nesse estudo por meio de atividades teatrais bem como o uso de recursos visuais diversificados propiciaram maior interação e a participaçáo tanto dos alunos ouvintes como dos alunos surdos dentro das atividades programadas. No entanto, cabe destacar que o domínio da Língua de Sinais é fundamental para o desenvolvimento cognitivo, linguístico e social da criança surda, conduzindo-a ao aprendizado da Língua Portuguesa. Nesse sentido, considera-se importante o ensino de Língua de Sinais aos alunos com surdez, por meio de um adulto fluente nessa língua e também a inserção do intérprete de Libras em sala de aula.

\section{Referências}

BARBOSA, F. V.; LICHTIG, I. Protocolo do perfil das habilidades de comunicação de crianças surdas. Revista Estudo de Linguagem, Belo Horizonte, v. 22, n. 1, p. 95-118, 2014.

BARDIN, L. Análise de conteúdo.Tradução de Lis Reto e Augusto Pinheiro. Lisboa: Ediçôes 70, 2004.

BRASIL. Ministério da Educação. Secretaria de Educação Especial. Atendimento Educacional Especializado para Pessoas com Surdez. Brasília: MEC/SEEP, 2007.

CARVALHO, A. M. P. O uso do vídeo na tomada de dados: pesquisando o desenvolvimento do ensino em sala de aula. Pro-posiçóes, v. 7, n. 1, p. 5-13, 1996.

DADALTO, E. V.; GOLDFELD. G. Características comuns à narrativa oral de crianças na pré- alfabetização. Revista CEFAC, v. 11, n. 1, p. 42-49, 2009.

DELGADO, S. M. M. O papel do interlocutor no processo de interaçấo e comunicaçáo com jovens não- falantes. In: NUNES, L.R.O.P. et al. (Org.). Comunicar é preciso: em busca das melhores práticas na educaçâa do aluno com deficiência. Marília: ABPEE, 2011, p. 59- 69.

GEUSELI, Z. A narrativa em Língua de Sinais: um olhar sobre classificadores. In: QUADROS, R.M.; STUMPF, M.R. (Org.). Estudos Surdos IV. Petrópolis, Rio de Janeiro: Arara Azul, 2009, p. 112- 122.

GOLDFELD, M. Sócio- interacionismo e Surdez. In: GOLDFELD, M. (Org.). A criança surda: linguagem e cognição numa perspectiva sócio- interacionista. São Paulo: Plexus Editora, 2001, p. 44- 112.

GUARDA, N. S.; DELIBERATO, D. Caracterização dos enunciados de um aluno não- falante usuário de recurso suplementar de comunicação durante a construção de histórias. Revista Brasileira de Educaçáo Especial, Marília, v. 12, n. 2, p. 269-288, 2006.

HACHIMINE, A. H. F. O recontar de histórias em Libras por crianças surdas. 2006. 130 f. Dissertação (Mestrado em Educação) - Centro Universitário Moura Lacerda, Ribeirão Preto, 2006. 
LACERDA, C. B. F.; LODI, A. C. B. O desenvolvimento do narrar em crianças surdas: o contexto de grupo e a importância da língua de sinais. Temas sobre Desenvolvimento, v. 15, n. 85-86, p. 45-53, 2006.

MAYER-JONHSON, R. The picture communication symbols P. C. S. Software Boardmaker. Porto Alegre: Clik Tecnologia Assistiva, 2004

MEDINA, F. D. D.; DELIBERATO, D. Descrição das habilidades linguísticas de uma criança com paralisia cerebral durante atividades de histórias por meio da comunicaçáo alternativa. In: MANZINI, E. J.; MARQUEZINE, M. M.; BUSTO, R. M. (Orgs.). Questóes da linguagem na educaçáo especial. Sáo Carlos, ABPEE, 2014, p. 9-22.

MERSELIAN, K. T.; VITALIANO, C. R. Análise das condições organizadas em uma escola para promover a inclusão de alunos surdos. Revista Lusófona de Educaçáo, n. 19, p. 85-101, 2011.

MOURA, M. C. Surdez e Linguagem. In: LACERDA, C. B. F.; SANTOS L. F. (Orgs.). Tenho um aluno surdo, e agora? Introdução à Libras e educação de surdos. São Carlos: EduFScar, 2013, p. 13- 26.

NUNES, L. R. O. P. et al. Narrativas sobre fotos e vídeos e narrativas livres através de sistema gráfico de Comunicaçâo Alternativa. In: NUNES, L. R. O. P. (Org.). Favorecendo o desenvolvimento da comunicaçáo em crianças e jovens com necessidades educacionais especiais. Rio de Janeiro: Dunya, 2003, p. 142-169.

OBELAR, F. A importância da mediação no contexto de uma escola inclusiva. In: NUNES, L. R. O. P. et al. (Org.). Comunicar é preciso: em busca das melhores práticas na educação do aluno com deficiência. Marília :ABPEE, 2011, p. 71-79.

PERRONI, M. C. O desenvolvimento do discurso narrativo. São Paulo: Martins Fontes, 1992.

PINOTTI, K. J.; BOSCOLO, C. C. A dramatização como estratégia de aprendizagem da linguagem escrita para o deficiente auditivo. Revista Brasileira de Educaçáo Especial, Marília, v. 14, n. 1, p. 121-140, 2008.

PONSONI, A. Comunicaçáo Suplementar e alternativa no discurso narrativo do aluno com paralisia cerebral. 2010. 178f. Dissertaçáa (Mestrado em Educação) - Faculdade de Filosofia e Ciências, Universidade Estadual Paulista, Marília, 2010.

SILVA, A. C.; MEDEIROS, M. C. M.; LORENSI, V. M. O desenvolvimento do processo de letramento do aluno surdo a partir das experiências visuais proporcionadas pela literatura infantil. Revista de Educaçáo do Ideau, v. 5, n. 12, p. 1-12, 2010.

SILVA, A. N.; MANZINI, E. J.; DELIBERATO, D. Estratégias de mediação em atividade de reconto de histórias com alunos sem oralidade. Séries - Estudos, Campo Grande-MS, n. 28, p. 119-134, 2009.

SOUZA, L. O.; BERNARDINO, A. D. A contação de histórias como estratégia pedagógica na Educação Infantil e Ensino Fundamental. Educere et Educare, v. 6, n. 12, p. 235- 249, 2011.

TRIVÑOS, A. N. S. Introdução à pesquisa em ciências sociais: a pesquisa qualitativa em educação. São Paulo, Atlas, 1992.

VON TETZCHNER, S. Enunciados de múltiplos símbolos no desenvolvimento da linguagem gráfica. In: NUNES, L. R. O. P. (Org.). Favorecendo o desenvolvimento da comunicaçáo em crianças e jovens com necessidades educacionais especiais. Rio de Janeiro: Dunya, 2003, p. 173- 201.

et al. Inclusão de crianças em educação pré- escolar regular utilizando comunicação suplementar e alternativa. Revista Brasileira de Educação Especial. Marília, v. 11, n. 2, p. 151-184, mai./ago. 2005.

Suporte ao desenvolvimento da comunicação suplementar e alternativa. In: DELIBERATO, D.; et al. (Orgs.). Comunicaçáo alternativa: teoria, prática, tecnologia e pesquisa. Săo Paulo: Memnon Ediçốes Científicas, 2009, p. 14-27. 
Ana Claudia Tenor - Débora Deliberato

\section{Correspondência}

Ana Claudia Tenor - Núcleo de Atendimento Pedagógico Especializado, Secretaria Municipal de Educação Botucatu-SP. Rua Amando de Barros, 1520, Centro, CEP: 18600-050 - Botucatu, São Paulo - Brasil.

E-mail: anatenor@yahoo.com.br - delibera@marilia.unesp.br

Recebido em 07 de março de 2015

Aprovado em 03 de novembro de 2015 